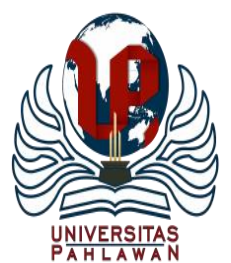

Edukatif : Jurnal Ilmu Pendidikan Volume 3 Nomor 5 Tahun 2021 Halm 2355 - 2361

EDUKATIF: JURNAL ILMU PENDIDIKAN

Research \& Learning in Education

https://edukatif.org/index.php/edukatif/index

\title{
Pengaruh Biaya Pendidikan terhadap Keputusan memilih Lembaga Pendidikan
}

\author{
Ulil Amri ${ }^{1 凶}$, Yahya $^{2}$ \\ Universitas Negeri Padang, Indonesia ${ }^{1,2}$ \\ E-mail : ulilamri845@ gmail.com ${ }^{1}$, yahyatambunan@ fip.unp.ac.id ${ }^{2}$
}

\begin{abstract}
Abstrak
Biaya pendidikan merupakan metode penelitian yang dipergunakan adalah metode kepustakaan (library research) dengan menggali berbagai penelitian yang relevan baik dari buku-buku maupun jurnal-jurnal.Hasil penelitian ini adalah kebjikan pendidikan di Indonesia dari masa kemasa terus mengalami perubahan jika dimasa orde ditekankan suatu kebijakan pendidikan yang merujuk kepada isu nasionalisasi dan ideologisasi. Filosofi pendidikan diwajibkan berdasarkan Pancasila dan Manipol (Manipesto politik) UUD1945 yang materinya berorientasi pada sosialisme dalam perspektif Indonesia, kemudian pada orde baru kebijakan sentralistik, pada masa reformasi bersifat reformatif dan revolusioner.
\end{abstract}

Konsitensi, Kebijakan, Pendidikan.

Abstract

The cost of education is. The research method used is the library research method by exploring various relevant studies both from books and journals. educational policy that refers to the issue of nationalization and ideologicalization. The philosophy of education is required based on Pancasila and the Manipol (Political Manipesto) of the 1945 Constitution whose material is oriented towards socialism in the Indonesian perspective, then in the new order of centralized policy, during the reformation period it was reformative and revolutionary.

Keywords: Consistency, Policy, Education.

Copyright (c) 2021 Ulil Amri, Yahya

$\triangle$ Corresponding author

Email : ulilamri845@gmail.com

DOI $\quad:$ https://doi.org/10.31004/edukatif.v3i5.786 


\section{PENDAHULUAN}

Pendidikan dipandang sebagai penyumbang yang sangat besar terhadap kemajuan suatu bangsa, serta merupakan wahana dalam menerjemahkan pesan-pesan konstitusi serta sdaran dalam membangun watak bangsa (Nation Character Building). Kecerdasan yang dimiliki oleh masyarakat tentu saja akan memberikan nuansa yang cerdas pula yang secara progresif akan membentuk kemandirian. Dalam membentuk kualitas pendidikan yang dapat mengantarkan masyarakat yang cerdas dan mandiri tersebut maka dibutuhkan suatu kerangka sistem dalam penyelenggaran pendidikan yang dituangkan dalam suatu kebijakan yang ditetapkan.

Dimasa sekarang kesempatan untuk memperoleh pendidikan yang lebih layak, sangat terbuka untuk siapa saja, hal ini disebabkan karena sudah banyak bermunculan jasa-jasa pendidikan yang menawarkan berbagai macam pendidikan yang sangat menarik, dengan berbagai penawarkan yang diberikan kepada masyarakat agar masyarakat memilih lembaga pendidikan tersebut, sehingga calon peserta didik ataupun calon mahasiswa dapat memperoleh harapan dan layanan yang baik dalam mengkonsumsi produk jasa pendidikan tersebut(Fahriansyah dan Zubir 2015).

Akan tetapi salah satu permasalahan dalam dunia pendidikan Indonesia adalah masalah biaya pendidikan, karena memang sudah menjadi rahasia umum, biaya pendidikan di Indonesia tergolong sangat mahal dan sangat memberatkan masyarakat(N. U. Hadi dan Murti 2018)

Hal ini mengakibatkan bahwa kualitas pendidikan Indonesia terus berada dalam pada tingkat bawah, menurut survei Polical and Economic Risk Consultant (PERC), kualitas pendidikan Indonesia berada pada urutan ke-12 dari 12 Negara di Asia. Indonesia berdasarkan hasil survei dari lembaga yang sama Indonesia hanya berpredikat sebagai follower bukan sebagai pemimpin teknologi dari 53 negara di Dunia (Fahriansyah dan Zubir 2015).

Padahal jika dipahami secara baik, sesungguhnya investasi pendidikan merupakan investasi manusia yang dapat menjadikan manusia memiliki daya saing, mampu untuk berkaya, serta lebih mampu memecahkan berbagai permasalahan yang ditemukannya dalam kehidupan (Purba 2018), banyak faktor yang menjadi seseorang memilih lembaga pendidikan yang akan menempanya untuk memiliki daya saing dalam kehidupan pasca keluar dari lembaga pendidikan, salah satunya adalah biaya pendidikan (Supardin, Ninik Indrawati n.d.).

Berdasarkan permasalahan di atas, maka tertarik penulis melakukan penelitian tentang bagaimana pengaruh biaya pendidikan terhadap keputusan memilih lembaga pendidikan, dengan menganalisis jurnaljurnal dan penelitian yang relevan lainnya.

\section{METODE PENELITIAN}

Penelitian ini berbentuk penelitan kepustakaan (library research), yaitu serangkaian penelitian yang berkenaan dengan metode pengumpulan data pustaka, atau penelitian yang objek penelitiannya digali melalui beragam informasi kepustakaan (buku, ensiklopedi, jurnal ilmiah, koran, majalah, dan dokumen) (S. Hadi 2000). Kajian pustaka ini dilakukan penulis dengan mengkaji tulisan ilmiah seperti buku, artikel dan jurnal. Jumlah literatur yang dipakai sebagai bahan acuan penulis dalam kajian ini yang berkaitan dengan kebijakan pemerintah terhadap pendidikan Indonesia. Kemudian penulis mengidentifikasi titik temu dari data-data primer dan sekunder yang diperoleh mengenai kebijakan-kebijakan tersebut. Adapun harapan adanya kajian ini dapat memotivasi setiap individu dalam memajukan pendidikan di Indonesia menjadi lebih baik. Metode ini dipilih penulis karena efektif untuk mengkaji dan menganalisis mengenai kebijakan pemerintah terhadap pendidikan di Indonesia, karena kajian ini dianalisis penulis setiap kejadian sesuai dengan urutan waktunya. 


\section{HASIL DAN PEMBAHASAN PENELITIAN}

\section{Pengertian Pembiayaan Pendidikan}

Biaya didefinisikan sebagai pergorbanan ekonomis yang dibuat guna memperoleh barang ataupun jasa. Secara bahasa biaya dapat diartikan sebagai pengeluaran dalam istilah ekonomi biaya dapat berupa uang atau bentuk meneter lainnya(Supriadi 2006).

Kemudian Biro Perencanaan Depdikbud yang dikutip oleh Suhardan, menjelaskan bahwa biaya pendidikan adalah biaya yang harus dikeluarkan baik oleh perorangan, keluarga,masyarakat, ataupun lembaga penyelenggara pendikan untuk memperoleh pendidikan yang diingginkanya (Suhardan, dkk 2012).

Suhardan juga mendefinisikan biaya pendidikan adalah total biaya yang dikeluarkan, baik itu dikeluarkan oleh individu peserta didik, keluarga yang menyekolahkan anaknya, warga masyarakat secara perorangan ataupun kelompok, yang dikeluarkan oleh pemerintah demi kelancaran pendidikan (Suhardan, dkk 2012).

Menurut Yahya yang dikutip Mulyono menjelaskan bahwa biaya pendidikan merupakan suatu unsur yang menentukan dalam mekanisme penganggaran. Biaya pendidikan dipengaruhi oleh tingkat efisiensi dan efektivitas kegiatan dalam sebuah organisasi pendidikan dalam upaya mencapai tujuan pendidikan (Mulyono 2010).

Dari penjelaskan di atas penulis mengambil kesimpulan bahwa biaya pendidikan merupakan biaya keseluruhan yang harus dikeluarkan oleh individu, keluarga, kelompok masyarakat, ataupun instansi pendidikan guna menunjang kegiatan belajar peserta didik pada lingkungan pendidikan formal maunpun non formal.

\section{Pengaruh Biaya Pendidikan Terhadap Keputusan Memilih Lembaga Pendidikan}

Penelitian ini melibatkan 8 artikel jurnal tentang Pengaruh Pendidikan terhadap Keputusan Memilih Lembaga Pendidikan. Berikut hasil penelitian (artikel jurnal) yang menjadi sumber dalam penelitian ini:

1. Analisis Pengaruh biaya dan Lokasi terhadap keputusan Mahasiswa Memilih Universitas Terbuka (Studi Pada mahasiswa UPBJJ-UT Pontianak), oleh Fahriansyah dan Edward Zubir. Penelitian ini dilakukan di UPBJJ-UT Pontianak dengan jumlah sampel pada penelitian ini akan diambil sebanyak 150 orang (Zubir 2015).

2. Pengaruh Motivasi, Biaya Pendidikan dan Lama Pendidikan terhadap Minat Mahasiswa Akuntansi Mengikuti Pendidikan Akuntansi (PPAk) di Universitas Dharma Andalas, oleh Muhammad Rivandi. Penelitian ini dilakukan di Universitas Dhara Andalas, dengan 152 Orang subjek penelitian.(Rivandi 2021).

3. Analisis Biaya Pendidikan dan Kondisi Sosial Ekonomi Orang Tua terhadap Keputusan Siswa Memilih Sekolah Di SMP Negeri 1 Karangrejo Tahun Ajaran 2017/2018 oleh Nafik Umurul Hadi, bertempat di SMP Negeri 1 Karangtejo dengan 81 orang siswa yang menjadi objek penelitian. (Supardin, Ninik Indrawati n.d.).

4. Pengaruh Kualitas Pelayanan, Biaya Pendidikan, dan Kelompok Referensi terhadap Keputusan Mahasiswa Pendidikan Ekonomi Memilih pada Program Studi Pendidikan Ekonomi oleh Supardin, yang bertempat di Fakultas Ekonomika dan Bisnis Universitas Kanjruhan Malang, dengan subjek penelitian berjumlah 62 orang(Supardin, Ninik Indrawati n.d.).

5. Pengaruh Faktor Budaya dan Biaya Pendidikan terhadap Keputusan Mahasiswa Asing dalam Memilih Universitas Islam Negeri Sultan Syarif Kasim Riau oleh Elisanovi yang bertempat di UIN Sultan Syafrif Kasim Riau dengan subjek penelitian berjumlah 100 orang responden (Elisanovi 2015).

6. Pengaruh Persepsi tentang Fasilitas, Biaya Pendidikan, Kualitas dan Lokasi terhadap Keputusan Siswa Memilih Sekolah,oleh Trian Yohandri, yang bertempat di Darma Bangsa Bandar Lampung, dengan subjek penelitian berjumlah 97 orang siswa (Yohandri 2014). 
7. Analisis Pengaruh Brand Image, Biaya Pendidikan, dan Fasilitas Pendidikan terhadap Keputusan Mahasiswa Melanjutkan Studi pada Program Diploma III Fakultas Ekonomi Universitas Diponegoro Semarang. Oleh Karina Pradityas Putri, bertempat di Universitas Diponegoro Semarang, dengan jumlah subjek penelitian para mahasiswa Program Diploma III FE Undip yang masih aktif, artinya masih menempuh studi pada Program Diploma III FE Undip (Putri n.d.).

8. Reputasi Universitas, Biaya Kuliah, Fasilitas Perkuliahan dan Keputusan Mahasiswa Memilih Program Studi Manajemen Universitas Flores: Studi pada Mahasiswa Program Studi Manajemen Angkatan 2019, yang ditulis oleh Yosafat Kristianus Bao, dengan subjek penelitian adalah seluruh mahasiswa Program Studi Manajemen, Fakultas Ekonomi Universitas Flores angkatan 2019 yang berjumlah 131 orang (Bao n.d.)

Berdasarkan hasil penelitian dari berbagai jurnal di atas, diperoleh gambaran sebagai berikut:

Tabel 1 Hasil Penelitian tentang Pengaruh Biaya Pendidikan terhadap Keputusan Memilih Lembaga Pendidikan.

\begin{tabular}{|c|c|c|c|}
\hline No & Judul Penelitian & Penggarang & Hasil Penelitian \\
\hline 1 & $\begin{array}{lr}\text { Analisis } & \text { Pengaruh biaya } \\
\text { dan Lokasi } & \text { Terhadap } \\
\text { keputusan } & \text { Mahasiswa } \\
\text { Memilih } & \text { Universitas } \\
\text { Terbuka } & \text { (Studi Pada } \\
\text { mahasiswa } & \text { UPBJJ-UT } \\
\text { Pontianak) } & \\
\end{array}$ & $\begin{array}{l}\text { Edward } \\
\text { Zubir }\end{array}$ & $\begin{array}{l}\text { Biaya Berpengaruh terhadap } \\
\text { keputusan mahasiswa dalam } \\
\text { memilih UTUPBJ Pontianak } \\
\text { secara signifikan }\end{array}$ \\
\hline 2 & $\begin{array}{lr}\text { Pengaruh Motivasi, Biaya } \\
\text { Pendidikan dan Lama } \\
\text { Pendidikan } & \text { Terhadap } \\
\text { Minat } & \text { Mahasiswa } \\
\text { Akuntansi } & \text { Mengikuti } \\
\text { Pendidikan } & \text { Akuntansi } \\
\text { (PPAk) di } & \text { Universitas } \\
\text { Dharma Andalas }\end{array}$ & $\begin{array}{l}\text { Muhammad } \\
\text { Rivandi }\end{array}$ & $\begin{array}{l}\text { Biaya pendidikan berpengaruh } \\
\text { signifikan terhadap minat siswa } \\
\text { mengikuti PPAk yang } \\
\text { diindikasikan dengan nilai yang } \\
\text { signifiikan } 0,004 \text {. }\end{array}$ \\
\hline 3 & $\begin{array}{l}\text { Analisis Biaya Pendidikan } \\
\text { dan Kondisi Sosial } \\
\text { Ekonomi Orang Tua } \\
\text { terhadap Keputusan Siswa } \\
\text { Memilih Sekolah Di SMP } \\
\text { Negeri } 1 \text { Karangrejo Tahun } \\
\text { Ajaran 2017/2018 }\end{array}$ & $\begin{array}{l}\text { Nafik } \\
\text { Umurul Hadi }\end{array}$ & $\begin{array}{l}\text { Ada pengaruh yang signifikan } \\
\text { antara biaya pendidikan } \\
\text { terhadap keputusan siswa } \\
\text { memilih sekolah di SMP Negeri } \\
1 \text { Karangrejo dengan nilai } \\
\text { thitung dari X1 Terhadap Y } \\
\text { senilai thitung }(3,693)>\text { ttabel } \\
(1,987) \text {. }\end{array}$ \\
\hline 4 & $\begin{array}{lr}\text { Pengaruh } & \text { Kualitas } \\
\text { Pelayanan, } & \text { Biaya } \\
\text { Pendidikan, dan } & \text { Kelompok } \\
\text { Referensi } & \text { terhadap } \\
\text { Keputusan } & \text { Mahasiswa } \\
\text { Pendidikan } & \text { Ekonomi } \\
\text { Memilih Pada } & \text { Program } \\
\text { Studi Pendidikan Ekonomi }\end{array}$ & Sup & $\begin{array}{l}\text { Biaya pendidikan berpengaruh } \\
\text { tehadap keputusan mahasiswa, } \\
\text { dengan nilai thitung sebesar - } \\
2.093 \text { dan taraf signifikansi } \\
\text { sebesar } 0,041 \text {. }\end{array}$ \\
\hline 5 & $\begin{array}{l}\text { Pengaruh Faktor Budaya } \\
\text { dan Biaya Pendidikan } \\
\text { terhadap } \\
\text { Mahasiswa Asing dalam } \\
\text { Memilih Universitas Islam } \\
\text { Negeri Sultan Syarif Kasim } \\
\text { Riau }\end{array}$ & Elisa & $\begin{array}{l}\text { Hasil penelitian ini } \\
\text { menunjukkan secara parsial } \\
\text { variabel budaya berpengaruh } \\
\text { terhadap keputusan mahasiswa } \\
\text { asing memilih UIN Suska Riau } \\
\text { sedangkan variabel biaya } \\
\text { pendidikan tidak berpengaruh }\end{array}$ \\
\hline
\end{tabular}




\begin{tabular}{|c|c|c|c|}
\hline No & Judul Penelitian & Penggarang & Hasil Penelitian \\
\hline & & & $\begin{array}{l}\text { terhadap keputusan mahasiswa } \\
\text { asing memilih UIN Suska Riau. } \\
\text { Nilai t hitung untuk variable } \\
\text { faktor biaya pendidikan sebesar } \\
\text { - } 0.981 \text { dengan tingkat } \\
\text { signifikansi } 0.330 \text { yang lebih } \\
\text { besar dari signifikansi } \alpha(0.05) \text {. }\end{array}$ \\
\hline 6 & $\begin{array}{l}\text { Pengaruh Persepsi tentang } \\
\text { Fasilitas, Biaya } \\
\text { Pendidikan, Kualitas dan } \\
\text { Lokasi terhadap Keputusan } \\
\text { Siswa Memilih Sekolah }\end{array}$ & $\begin{array}{l}\text { Trian } \\
\text { Yohandri }\end{array}$ & $\begin{array}{l}\text { Ada Pengaruh Biaya Pendidikan } \\
\text { Terhadap Keputusan Siswa } \\
\text { Memilih Sekolah }\end{array}$ \\
\hline 7 & \begin{tabular}{lr}
\multicolumn{2}{l}{ Analisis Pengaruh Brand } \\
Image, Biaya & Pendidikan, \\
dan Fasilitas & Pendidikan \\
terhadap & Keputusan \\
Mahasiswa & Melanjutkan \\
Studi pada & Program \\
Diploma III & Fakultas \\
Ekonomi & Universitas \\
Diponegoro Semarang
\end{tabular} & $\begin{array}{l}\text { Karina } \\
\text { Pradityas } \\
\text { Putri, }\end{array}$ & $\begin{array}{l}\text { Hasil pengujian fungsi regresi } \\
\text { yang dilakukan menunjukkan } \\
\text { bahwa variabel biaya } \\
\text { pendidikan memiliki nilai } \\
\text { koefisien terkecil yaitu sebesar } \\
\text { 0,107. Ini menunjukkan bahwa } \\
\text { variabel biaya pendidikan } \\
\text { memiliki pengaruh yang paling } \\
\text { kecil dalam mempengaruhi } \\
\text { keputusan konsumen dalam } \\
\text { melanjutkan studi ke Program } \\
\text { DIII FE Undip }\end{array}$ \\
\hline 8 & $\begin{array}{l}\text { Reputasi Universitas, } \\
\text { Biaya Kuliah, Fasilitas } \\
\text { Perkuliahan dan Keputusan } \\
\text { Mahasiswa Memilih } \\
\text { Program Studi Manajemen } \\
\text { Universitas Flores: Studi } \\
\text { pada Mahasiswa Program } \\
\text { Studi Manajemen } \\
\text { Angkatan 2019. }\end{array}$ & $\begin{array}{l}\text { Yosafat } \\
\text { Kristianus } \\
\text { Bao }\end{array}$ & $\begin{array}{l}\text { Hasil analisis menunjukkan } \\
\text { bahwa terdapat pengaruh positif } \\
\text { dan signifikan antara reputasi } \\
\text { universitas, biaya kuliah, dan } \\
\text { fasilitas perkuliahan secara } \\
\text { bersama-sama terhadap } \\
\text { keputusan mahasiswa memilih } \\
\text { Prodi Manajemen di Universitas } \\
\text { Flores. Hal ini ditunjukkan } \\
\text { dengan hasil uji F yang } \\
\text { mempunyai nilai signifikansi } \\
0,000 \text { atau < 0,05. Nilai R2 } \\
\text { sebesar 0, } 965 \text { atau } 96,5 \% \text {, jadi } \\
\text { dapat dikatakan bahwa } 96,5 \% \\
\text { keputusan masiswa } \\
\text { dipengaruhi oleh reputasi } \\
\text { universitas, biaya kuliah, dan } \\
\text { fasilitas perkuliahan. Sedangkan } \\
\text { sisanya 3,5\% dipengaruhi } \\
\text { variabel lain yang tidak diteliti } \\
\text { dalam penelitian ini }\end{array}$ \\
\hline
\end{tabular}

(Sumber: Olahan Penulis, 2021)

Berdasarkan data di atas terlihat bahwa biaya pendidikan memiliki pengaruh terhadap keputusan dalam memilih lembaga pendidikan seperti yang hasil penelitian oleh para peneliti. Pada Jurnal pertama penelitian yang dilakukanEdward Zubir ditemukan bahwa biaya berpengaruh terhadap keputusan mahasiswa dalam memilih UTUPBJJ Pontianak secara signifikan. Kemudian jurnal yang ke dua oleh Muhammad Rivandi yang menjelaskan dalam hasil penelitiannya bahwa biaya pendidikan berpengaruh signifikan terhadap minat siswa mengikuti PPAk yang diindikasikan dengan nilai yang signifiikan 0,004. 
Pada Jurnal ketiga oleh Nafik Umurul Hadi di temukan bahwa Ada pengaruh yang signifikan antara biaya pendidikan terhadap keputusan siswa memilih sekolah di SMP Negeri 1 Karangrejo dengan nilai thitung dari X1 terhadap Y senilai thitung $(3,693)>$ ttabel $(1,987)$. Pada Jurnal keempat oleh Supardin ditemukan bahwa Biaya pendidikan berpengaruh tehadap keputusan mahasiswa, dengan nilai thitung sebesar-2.093 dan taraf signifikansi sebesar 0,041.

Jurnal ke lima oleh Elisanovi ditemukan bahwa hasil penelitian ini menunjukkan secara parsial variabel budaya berpengaruh terhadap keputusan mahasiswa asing memilih UIN Suska Riau sedangkan variabel biaya pendidikan tidak berpengaruh terhadap keputusan mahasiswa asing memilih UIN Suska Riau. Nilai t hitung untuk variable faktor biaya pendidikan sebesar-0.981 dengan tingkat signifikansi 0.330 yang lebih besar dari signifikansi $\alpha(0.05)$.

Dalam jurnal ke enam oleh Trian Yohandri diperoleh hasil bahwa ada pengaruh biaya pendidikan terhadap keputusan siswa memilih sekolah, Kemudian pada jurnal yang ke tujuh oleh Karina Pradityas Putri dalam hasil penelitiannya menunjukan bahwa hasil pengujian fungsi regresi yang dilakukan menunjukkan bahwa variabel biaya pendidikan memiliki nilai koefisien terkecil yaitu sebesar 0,107 . Ini menunjukkan bahwa variabel biaya pendidikan memiliki pengaruh yang paling kecil dalam mempengaruhi keputusan konsumen dalam melanjutkan studi ke program DIII FE Undip.

Jurnal ke delapan oleh Yosafat Kristianus Bao menunjukan bahwa hasil analisis menunjukkan bahwa terdapat pengaruh positif dan signifikan antara reputasi universitas, biaya kuliah, dan fasilitas perkuliahan secara bersama-sama terhadap keputusan mahasiswa memilih Prodi Manajemen di Universitas Flores. Hal ini ditunjukkan dengan hasil uji $\mathrm{F}$ yang mempunyai nilai signifikansi 0,000 atau $<0,05$. Nilai R2 sebesar 0, 965 atau $96,5 \%$, jadi dapat dikatakan bahwa 96,5\% keputusan mahasiswa dipengaruhi oleh reputasi universitas, biaya kuliah, dan fasilitas perkuliahan. Sedangkan sisanya 3,5\% dipengaruhi variabel lain yang tidak diteliti dalam penelitian ini.

Berdasarkan hasil penelitian di atas dapat disimpulkan bahwa biaya pendidikan memiliki pengaruh terhadap keputusan seseorang dalam memilih lembaga pendidikan tempat dia menimba ilmu, ataupun tempat orang tua menitipkan anaknya menutut ilmu.

\section{KESIMPULAN}

Lembaga pendidikan terus berkembang baik yang formal maupun yang non formal, yang swasta maupun yang negeri. Berbagai upaya terus dilakukan oleh lembaga pendidikan tersebut dalam merekrut calon peserta didiknya (siswa/mahasiswa), dengan berbagai upaya yang dilakukan agar orang tua ataupun anak tertarik untuk menimba ilmu di lembaga pendidikan tersebut. Salah satu juga menjadi perhatian bagi para orang tua dan anak adalah disamping mutu juga adalah masalah biaya yang dipungut di lembaga pendidikan tersebut. Hal ini terbukti dari beberapa penelitian yang dilakukan oleh berbagai peneliti seperti yang telah diuraikan diatas membuktikan bahwa masalah biaya memiliki pengaruh yang signifikan terhadap seseorang mengambil keputusan untuk memilih salah satu lembaga pendidikan yang akan dipilihnya untuk bersekolah ataupun kuliah.

\section{UCAPAN TERIMA KASIH}

Penulis mengucapkan terima kasih pada pihak yang telah membantu suksesnya penelitian ini, terutama bapak Dr. Yahya, M.Pd. selaku dosen pembimbing sehingga selesai makalah ini.

\section{DAFTAR PUSTAKA}

Bao, Yosafat Kristianus. "Reputasi Universitas, Biaya Kuliah, Fasilitas Perkuliahan Dan Keputusan 
2361 Pengaruh Biaya Pendidikan terhadap Keputusan Memilih Lembaga Pendidikan - Ulil Amri, Yahya DOI: https://doi.org/10.31004/edukatif.v3i5.786

Mahasiswa Memilih Program Studi Manajemen Universitas Flores: Studi Pada Mahasiswa Program Studi Manajemen Angkatan 2019.” Analisis Edisi20 Ta.

Dkk, Dadang Suhardan. 2012. Ekonomi Dan Pembiayaan Pendidikan. Bandung: Alfabeta.

Elisanovi. 2015. "Pengaruh Faktor Budaya Dan Biaya Pendidikan Terhadap Keputusan Mahasiswa Asing Dalam Memilih Universitas Islam Negeri Sultan Syarif Kasim Riau.” Jurnal Al-Iqtishad, Edisi 11 II.

Fahriansyah, Dan Edward Zubir. 2015. "Analisis Pengaruh Biaya Dan Lokasi Terhadap Keputusan Mahasiswa Memilih Universitas Terbuka (Studi Pada Mahasiswa UPBJJ-UT Pontianak).” Integra 5: 3250 .

Hadi, Nafik Umurul, Dan Tri Kresna Murti. 2018. "Orang Tua Terhadap Keputusan Siswa Memilih Sekolah Di Smp Negeri 1 Karangrejo Tahun Ajaran 2017 / 2018.” (3).

Hadi, Sutrisno. 2000. Metodologi Reserach. Yogyakarta: Rake Sari.

Mulyono. 2010. Konsep Pembiayaan Pendidikan. Yogyakarta: Ar Ruzz Media Grup.

Purba, Rakhmawati. 2018. "Analisis Faktor-Faktor Yang Membedakan Pembiayaan Pendidikan Di Setiap Satuan Pendidikan Smk Negeri Kota Tebing Tinggi.” Wahana Inovasi Volume 7 N(Issn : 2089-8592).

Putri, Karina Pradityas. "Analisis Pengaruh Brand Image, Biaya Pendidikan, Dan Fasilitas Pendidikan Terhadap Keputusan Mahasiswa Melanjutkan Studi Pada Program Diploma III Fakultas Ekonomi Universitas Diponegoro Semarang." Http://Eprints.Undip.Ac.Id/30905/1/JURNAL.Pdf.

Rivandi, Muhammad. 2021. "Pengaruh Motivasi, Biaya Pendidikan Dan Lama Pendidikan Terhadap Minat Mahasiswa Akuntansi Mengikuti Pendidikan Akuntansi (Ppak) Di Universitas Dharma Andalas." Jurnal Ekonomi Dan Bisnis Dharma Andalas Volume 23.

Supardin, Ninik Indrawati, Walipah. "Pengaruh Kualitas Pelayanan, Biaya Pendidikan, Dan Kelompok Referensi Terhadap Keputusan Mahasiswa Pendidikan Ekonomi Memilih Pada Program Studi Pendidikan Ekonomi." Jurnal Riset Pendidikan Ekonomi (JRPE).

Supriadi, Dedi. 2006. Satuan Biaya Pendidikan Dasar Dan Menengah. Bandung: Remaja Rosdakarya.

Yohandri, Trian. 2014. "Pengaruh Persepsi Tentang Fasilitas, Biaya Pendidikan, Kualitas Dan Lokasi Terhadap Keputusan Siswa Memilih Sekolah.” JEE (Jurnal Edukasi Ekobis) Volume 2.

Zubir, Fahriansyah Dan Edward. 2015. "Analisis Pengaruh Biaya Dan Lokasi Terhadap Keputusan Mahasiswa Memilih Universitas Terbuka (Studi Pada Mahasiswa UPBJJ-UT Pontianak)." Integra Volume 05 . 